THE dextran sodium sulphate (DSS) induced colitis in mice was used as a experimental model to study the contractility of murine longitudinal colonic smooth muscle during inflammation. Smooth muscle segments of proximal, middle and distal colon were mounted in organ baths. Smooth muscle contraction was induced by carbachol, showing an aboral increase in activity, whereas in the inflamed middle colonic segment a marked decrease in activity was observed. The dilatative effect of sodium-nitroprusside (SNP) as a nitric oxide donor was investigated after precontraction by carbachol. Both in normal and DSS segments admin istration of SNP to isolated mouse colonic smooth muscle preparations caused regional differences in relaxation, the highest relaxation seen in normal proximal colonic tissue. However, this relaxation was markedly reduced in inflamed proximal preparations, associated with a diminished cGMP contents.

Key words: Colitis, Mice, Contractility, Carbachol, Nitric oxide, cGMP

\section{Diminished nitroprusside-induced relaxation of inflamed colonic smooth muscle in mice}

\author{
J. D. van Bergeijk, ${ }^{2}$ H. van Westreenen, ${ }^{1}$ P Adhien ${ }^{1}$ \\ and F. J. Zijlstra ${ }^{1, C A}$
}

${ }^{1}$ Department of Pharmacology, Faculty of Medicine and Health Sciences, Erasmus University, PO Box 1738, 3000 DR Rotterdam; ${ }^{2}$ Department of Gastroenterology, University Hospital Dijkzigt, Dr Molewaterplein 40, 3015 GD Rotterdam, The Netherlands

${ }^{\mathrm{CA}}$ Corresponding Author
Tel: $(+31) 104087550$
Fax: (+31) 104366839
Email: zijlstra@farma.fgg.eur.nl

\section{Introduction}

The dex tran sodium sulphate (DSS) induced colitis in mice $^{1}$ is at present a well documented experimental model to study formation of inflammatory mediators and the use of therapeutics in ulcerative colitis (UC). This mild colitis is mainly characterized by infiltration of neutrophils, diarrhoea, rectal blood and loss of body weight. ${ }^{2}$ Besides the disease dependent release of lipid mediators and cytokines, ${ }^{3}$ enhanced colonic nitric oxide (NO) generation could influence the disease activity in UC and Crohn's disease. Several investigators have demonstrated increased concentrations of $\mathrm{NO}$ in intestinal mucosa of patients with inflammatory bowel disease (IBD). ${ }^{4-6}$ Increased concentrations of NO could not only result in damage of epithelial cells and apoptosis, but also lead to mucosal vasodilatation, an increased vasopermeability and a decreased colonic motility. Therefore high mucosal levelds of endogenous NO may mediate gut motor disfunction and other clinical features as abdominal pain, malabsorption and granulomatous inflammation in IBD. ${ }^{7,8}$ As a result of dow nregulatory mechanisms, smooth muscle response to $\mathrm{NO}$ is inhibited by high endogenous NO production. Moreover reduction of NO synthase activity could lead to a reduced relaxation.

In this study we investigated the effect of NO from exogenous sodium nitroprusside (SNP) on both nor- mal and inflamed murine colonic smooth muscle preparations.

\section{Methods and Materials}

\section{Animals/tissues}

The study protocol had been approved by the local Animal Ethical Committee (no. 118-97-01). Colonic smooth muscle preparations were obtained from BALB/c mice (female, 20-22 g, IFFA Credo, France). Colitis was induced by adding $10 \%(\mathrm{w} / \mathrm{v})$ dextran sodium sulphate (MW > 500 000, Pharmacia, Sw eden) to their drinking water, ad libitum for 8 days. Controls received tap water. After overnight fastin mice were killed by cervical dislocation. Immediately thereafter the colon was removed. Total length (approx $90 \mathrm{~mm}$ ) was divided in proximal, middle and distal colonic segments.

\section{Disease activity score}

Upon sacrifice, the removed bowel was examined macroscopically. Signs of inflammation (diarrhoea, blood) and changes in tissue appearance (oedema, thickening) were scored (0-2). Pieces of proximal, middle and distal colon were taken for histological analysis. The sections were fixated in $3.6 \%$ buffered formalin, $\mathrm{pH} \mathrm{7,} \mathrm{and} \mathrm{embedded} \mathrm{in} \mathrm{paraffin} \mathrm{wax.}$ 
Sections cut at $5 \mu \mathrm{m}$ thickness and stained with haematotoxylin and azaflox in were examined under a light microscope using a $400 \times$ magnification. The histology score obtained from each section (blinded scored including inflammation $0-3$, damage/necrosis $0-3$ and regeneration $0-3$ ) ranged from 0 to 9 was combined with the macroscopic score $(0-3)$ and used as the disease activity score (DAS; $0-12) .{ }^{10}$

\section{Organ bath}

Whole longitudinal colonic smooth muscle preparations (including mucosa, circular layer and neuronal plexus) were mounted in $10 \mathrm{ml}$ double-jacketed organ baths containing Krebs solution heated to $37^{\circ} \mathrm{C}$ and continuously gassed with $5 \% \mathrm{CO}_{2}$ in $\mathrm{O}_{2}$. The contractile responses were measured isotonically using Penny \& Giles transducers (pre-load $500 \mathrm{mg}$ ). Cumulative contraction-response curves were prepared by adding agonists in small volumes. Preparations were pre-contracted with $300 \mathrm{mM} \mathrm{KCl}$, the optimum concentration found in blood vessel organ bath observations. ${ }^{11}$ After washing (three times bath fluid contents every $5 \mathrm{~min}$ ), contraction was induced by the muscarinic receptor agonist carbachol (Sigma Chemicals) in doses of $10^{-8}$ to $10^{-3} \mathrm{M}$, reaching stable maximal smooth muscle contraction. Contraction was expressed as mg displacement. Without washing relaxation by SNP (Sigma Chemicals) in doses of $8.4 .10^{-8}$ to $8.4 .10^{-4} \mathrm{M}$ was induced. Relaxation was expressed as percentage fall in contraction. After a second washing regime carbachol induced contraction $\left(10^{-3} \mathrm{M}\right)$ was antagonized by the $\beta_{2}$-receptor agonist salbutamol in doses of $10^{-8}$ to $10^{-3} \mathrm{M}$. Bath samples were taken for measurements of $\mathrm{NO}_{2} / \mathrm{NO}_{3}$ $\left(\mathrm{NO}_{\mathrm{x}}\right)$ and cyclic GMP (Biotrak-assay, Amersham, $\mathrm{UK}){ }^{3}$ Maximum $\left(\mathrm{EC}_{\max }\right)$ and half-maximum $\left(\mathrm{EC}_{50}\right)$ contractions and relaxations were calculated after computer programmed plotting of dose-response curve fitting. Results are expressed as mean \pm standard error. Statistical analys is included Wilcoxon's test for unpaired samples (in case of DAS activities) and Student's $t$-test (other observations).

\section{Results}

\section{Inflammation}

After macroscopic and microscopic evaluation we observed a mild to moderate disease activity in the DSS-induced colitis mice (DAS in proximal colon: 6.4 \pm 1.57 and in middle colon: $6.3 \pm 1.10)$. Distal colonic preparations tended to show a dimished DAS ( $4.4 \pm$ 0.79 ), mainly due to the absence of thickening, oedema, faecal blood and diarrhoea. Histologically inflammation was limited to mucosa and submucosa (neutrophil infiltrations), without involving muscular layers.

\section{Contractility}

In normal tissues we observed an increased contraction after carbachol in aboral direction (Fig. 1: distal > middle > proximal colon). In inflammation this carbachol-induced contraction was markedly reduced in middle colonic segments. In the non-inflamed

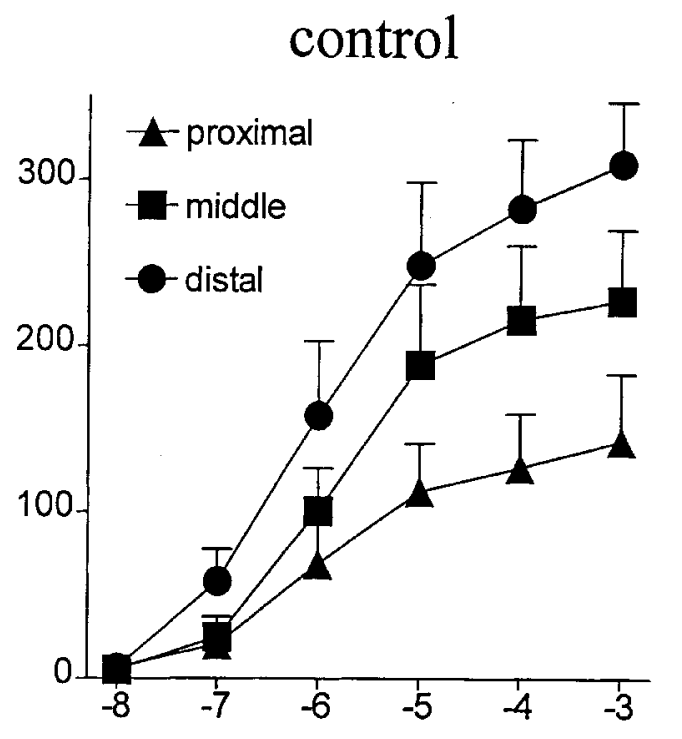

\section{DSS-colitis}

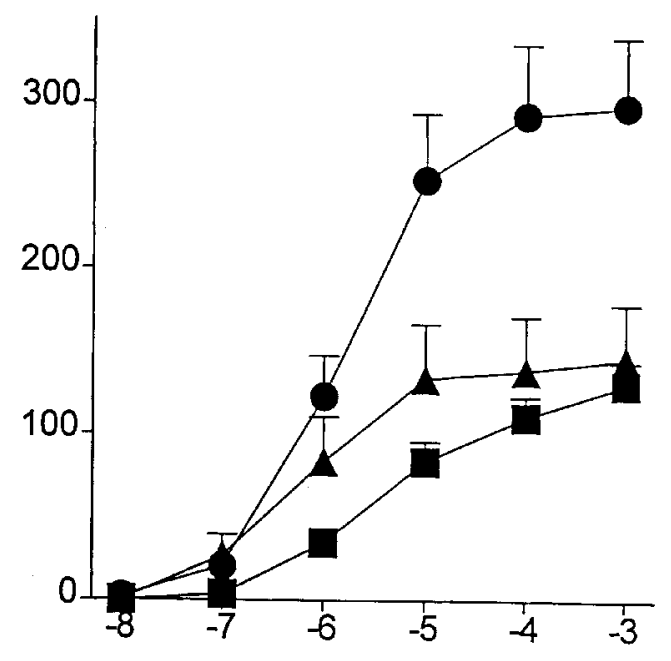

\section{carbachol (log dose)}

FIG. 1. Effect of carbachol induced contraction in mouse longitudinal colonic smooth muscle preparations in controls (left panel) and dextran sodium sulphate (DSS)-induced colitis (right panel). Contraction is expressed asmg displacement of the isotonic transducer. $n=8$. 


\section{control}

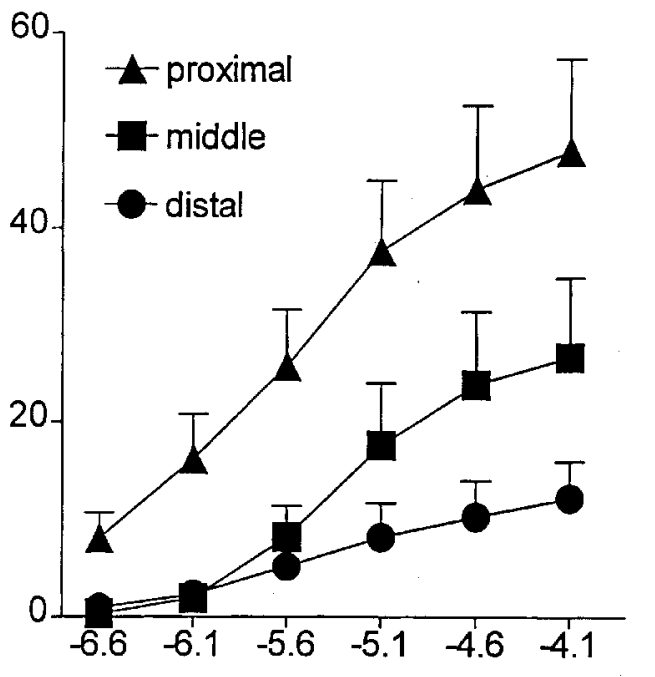

\section{DSS-colitis}

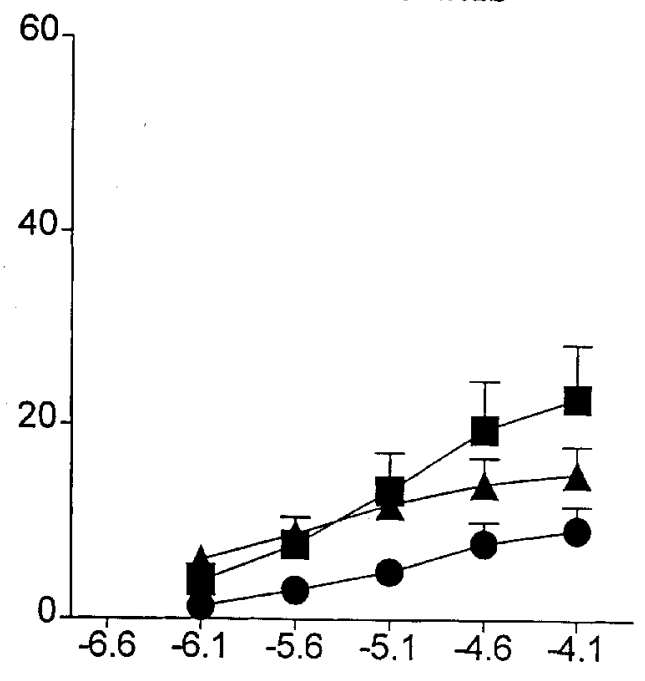

\section{nitroprusside (log dose)}

FIG. 2. Effect of sodium nitroprusside (SNP) relaxation in mouse longitudinal colonic smooth muscle preparations precontracted with carbachol $10^{-3} \mathrm{M}(100 \%)$ in controls (left panel) and dextran sodium sulphate (DSS)-induced colitis (right panel), expressed as percentage relaxation. $n=8$.

proximal colon SNP showed a much higher relax ation (mean $\mathrm{E}_{\mathrm{max}} 48 \%$ ) than those observed in middle (mean $\mathrm{E}_{\mathrm{max}}$ 27\%) and distal (mean $\mathrm{E}_{\mathrm{max}}$ 12\%) colonic preparations, precontracted by carbachol. Nitroprusside-induced relaxation however was significantly reduced $(\geq 70 \%)$ in DSS-induced inflamed proximal preparations (mean $\mathrm{E}_{\max } 15 \%$ ) and of the same magnitude as the middle (mean $\mathrm{E}_{\max } 22 \%$ ) and distal (mean $\mathrm{E}_{\max }$ 9\%) preparations which tended to decrease (Fig. 2). A similar pattern was observed after induction of salbutamol-evoked relaxations between controls and DSS preparations (Fig. 3), although the difference in relaxations between the proximal segments was less prominent.

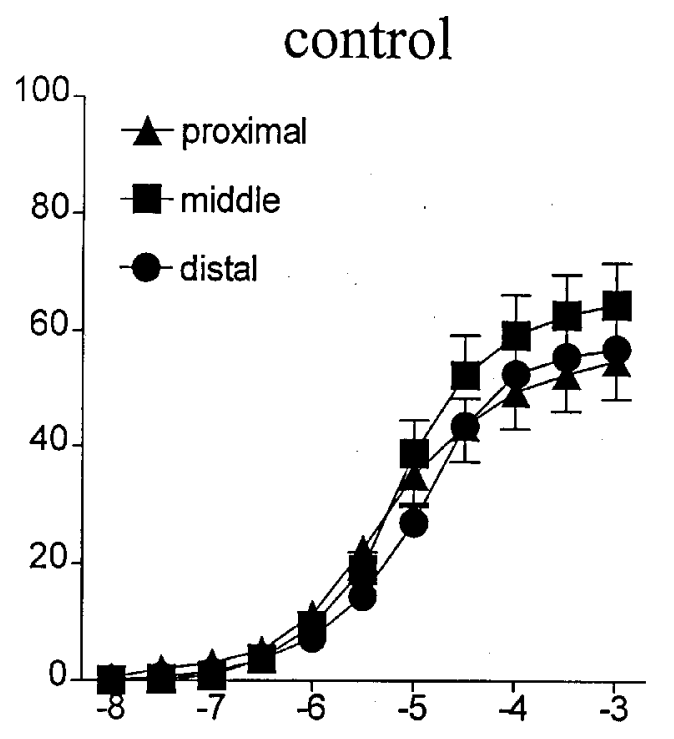

\section{DSS-colitis}

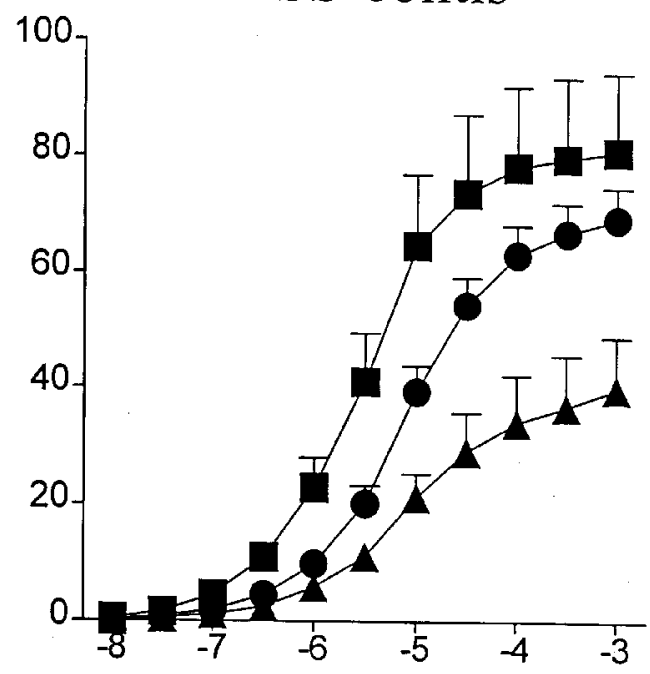

\section{salbutamol (log dose)}

FIG. 3. Effect of salbutamol induced relaxation in mouse longitudinal colonic smooth muscle preparations precontracted with carbachol $10^{-3} \mathrm{M}(100 \%)$ in controls (left panel) and dextran sodium sulphate (DSS)-induced colitis (right panel), expressed as percentage relaxation. $n=8$. 
Table 1. $\mathrm{NO}_{\mathrm{x}}$ release in organ baths $(\mu \mathrm{M})$ after carbachol $\left(10^{-3} \mathrm{M}\right)$ and nitroprusside $\left(8.410^{-4} \mathrm{M}\right)$ application $(\boldsymbol{n}=4)$

\begin{tabular}{|c|c|c|c|c|c|c|}
\hline & \multicolumn{3}{|c|}{ Controls } & \multicolumn{3}{|c|}{ DSS-colitis } \\
\hline & Resting & Carbachol & Carbachol + NP & Resting & Carbachol & Carbachol + NP \\
\hline $\begin{array}{l}\text { Proximal } \\
\text { Middle } \\
\text { Distal }\end{array}$ & $\begin{array}{l}174 \pm 9 \\
168 \pm 12 \\
171 \pm 7\end{array}$ & $\begin{array}{l}184 \pm 10 \\
135 \pm 33 \\
152 \pm 17\end{array}$ & $\begin{array}{l}860 \pm 39 \\
838 \pm 89 \\
770 \pm 65\end{array}$ & $\begin{array}{l}171 \pm 15 \\
170 \pm 17 \\
170 \pm 10\end{array}$ & $\begin{array}{l}166 \pm 13 \\
155 \pm 7 \\
159 \pm 5\end{array}$ & $\begin{array}{l}802 \pm 65 \\
712 \pm 46 \\
665 \pm 55\end{array}$ \\
\hline
\end{tabular}

Table 2. cGMP organ bath levels (nM) after carbachol $\left(10^{-3} \mathrm{M}\right)$ and nitroprusside $\left(8.410^{-4} \mathrm{M}\right)$ application ( $\left.n=4\right)$

\begin{tabular}{|c|c|c|c|c|c|c|}
\hline & \multicolumn{3}{|c|}{ Controls } & \multicolumn{3}{|c|}{ DSS-colitis } \\
\hline & Resting & Carbachol & Carbachol + NP & Resting & Carbachol & Carbachol + NP \\
\hline $\begin{array}{l}\text { Proximal } \\
\text { Middle } \\
\text { Distal }\end{array}$ & $\begin{aligned} 24 & \pm 12 \\
8 & \pm 7 \\
19 & \pm 11\end{aligned}$ & $\begin{array}{c}157 \pm 49 \\
48 \pm 3 \\
99 \pm 17\end{array}$ & $\begin{aligned} 609 & \pm 219 \\
98 & \pm 43 \\
188 & \pm 55\end{aligned}$ & $\begin{array}{l}4 \pm 4 \\
3 \pm 3 \\
9 \pm 6\end{array}$ & $\begin{array}{c}100 \pm 33 \\
32 \pm 7 \\
68 \pm 18\end{array}$ & $\begin{array}{c}138 \pm 33^{*} \\
42 \pm 14 \\
93 \pm 25\end{array}$ \\
\hline
\end{tabular}

${ }^{*} P<0.05$ DSS vs. controls.

\section{$\mathrm{NO}_{\mathrm{x}}$}

The net total NO release after addition of SNP was determined as $\mathrm{NO}_{2} / \mathrm{NO}_{3}$. No regional nor control-DSS differences were found (Table 1).

\section{Cyclic GMP}

In the bath fluids cGMP content was measured after SNP-evoked relaxation (Table 2). Levels measured in baths from DSS preparations were lower, although this was only significant in proximal preparations $(P<0.05$, Student's $t$-test $)$.

\section{Discussion}

Normal longitudinal colon smooth muscle contraction induced by carbachol showed an aboral increase. A marked decrease in activity was observed in the middle segment of the inflamed colon. However, no correlation was found between severity of inflammation and disturbed contractility, as carbachol-induced effects in the more inflamed colon were less pronounced. We found an increased SNP-induced relaxation in normal proximal tissue, which was observed in the most inflamed, proximal colonic smooth muscle preparations. Normal and inflamed proximal segments converted SNP into $\mathrm{NO}$, measured as $\mathrm{NO}_{\mathrm{x}}$ Cyclic GMP contents however were significantly decreased in the inflamed proximal colon bath fluid. This reduction in cGMP was correlated with the diminished SNP-induced relaxation.

In normal, non-inflamed rat colonic segments, Maehara et al. ${ }^{12}$ found no differences between NOevoked release of cGMP in proximal and distal preparations, although relaxation in proximal colon was more prominant than in distal colon. This effect was attributed however to the release of vasoactive intestinal peptide (VIP), a mediator with dilative properties, which only was detected in distal colon.

Our study is the first in which contractility was investigated in inflamed colonic preparations from DSS-mice. Very recently it was shown that in longitudinal strips from trinitrobenzenesulphonic acid (TNBS)-treated ileum in guinea pigs there was a twofold increase in maximal response induced by carbachol and histamine without modification of the $\mathrm{EC}_{50}$ values. ${ }^{13}$ This observation is in contrast with our present findings. This could be due to a different model of inflammation, as TNBS is a direct toxin to mucosal epithelium and DSS-induced inflammation is very likely triggered by changes in intestinal macrophage function and bacterial flora. ${ }^{14}$ In our model smooth muscles were not visibly altered. The marked neutrophil infiltration could contribute to an enhanced production of NO, which in turn will lead to a diminished smooth muscle contraction. Furthermore Martinolle et al. ${ }^{13}$ used the ileum from guinea pigs, and literature on NO production in both species and ileum is not available yet. Nitric oxide synthetase activity however was five-fold increased in mucosa taken from patients with ulcerative colitis, but unchanged in those from Crohn's disease. ${ }^{15}$ This indicates that cell-specific generation of inflammatory mediators or local susceptibility of smooth muscles will determine the outcome of $\mathrm{NO}$ production and contractility.

In controls the salbutamol induced relaxation was similar in all preparations. This indicates the presence of a normal second messenger system, which only was affected in inflamed proximal segments. After SNP application a significant decrease in cGMP levels 
was found. During chronic inflammation of the colon the ongoing production of NO could diminish guanylate cyclase activity resulting in a decreased relaxation.

It is also possible that carbachol-evoked cGMP release will influence the threshold necessary to obtain relaxation after pre-contraction with carbachol. Recently it was shown that the nerve stimulation-induced muscarinic NO release in the guinea pig likely is mediated by $M_{1}$ muscarinic receptor activation. ${ }^{16}$ Comparable with observations in lung diseases, negative feedback by $\mathrm{M}_{2}$ muscarinic receptor activation could be depleted in inflamed colonic tissue. ${ }^{17}$ In colitis this mechanism of action needs further investigation.

\section{References}

1. Okayasu I, Hatakeyama S, Yamada M, Ohkusa T, Inagaki Y, Nakaya R. A novel method in the induction of reliable experimental acute and chronic ulcerative colitis in mice. Gastroenterology 1990; 98: 694-702.

2. Zijlstra FJ, van Dijk JPM, Wilson JHP. Increased platelet activating factor synthesis in experimental colitis after diclofenac and 5-amino-salicylic acid. Eur J Pharm a col 1993; 249: R1-R2.

3. van Dijk APM, Keuskamp ZJ, Wilson JHP, Zijlstra FJ. Sequential release of cytokines, lipid mediators and nitric oxide in experimental colitis. Mediators Inflam $m$ 1995; 4: 186-190.

4. Rachmilewitz D, Stamler JS, Bachwich D, Karmeli F, Ackerman Z, Podolsky DK. Enhanced colonic nitric oxide generation and nitric oxide synthase activity in ulcerative colitis and Crohn's disease. Gut 1995; 36: $718-723$.

5. Tepperman BL, Brown JF, Whittle BJR. Nitric oxide synthase induction and intestinal epithelial cell viability in rats. Am J Physiol 1993; 265: G214-G218.
6. Middleton SJ, Shorthouse M, Hunter JO. Increased nitric oxide synthesis in ulcerative colitis. Lancet 1993; 341: 465-466.

7. Calignano A, Whittle BJR, di Rosa M, Moncada S. Involvement of endogenous nitric oxide in the regulation of rat intestinal motility in vivo. Eur I Pharmacol 1992; 229: 273-276.

8. Salzman AL. Nitric oxide in the gut. New Horizons 1995; 3: 33-45.

9. Suthamnatpong N, Hata F, Kanada A, TakeuchiT, Yagasaki O. Mediators of nonadrenergic, noncholinergic inhibition in the proximal, middle and distal regions of rat colon. Br J Pharmacol 1993; 108: 348-355.

10. Dieleman LA, Ridwan BU, Tennyson GS, Beagley KW, Bucy RP, Elson CO. Dextran sulphate sodium-induced colitis occurs in severe combined immunodeficient mice. Gastroenterology 1994; 107: 1643-1652.

11. Bax WA, Renzenbrink GJ, van der Linden EA, Zijlstra FJ, van HeuvenNolsen D, Fekkes D, Bos E, Saxena PR. Low-dose aspirin inhibits plateletinduced contraction of the human isolated coronary artery. A role for additional 5-hydroxytryptamine receptor antagonism against coronary vasopasm? Circulation 1994; 89: 623-629.

12. Maehara T, Fujita A, Suthamnatpong N, Takeuchi T, Hata F. Differences in relaxant effects of cyclic GMP on skinned muscle preparations from the proximal and distal colon of rats. Eur J Pharmacol 1994; 261: $163-170$.

13. Martinolle JP, Garcia-Villar R, Fioramonti J, Bueno L. Alte red contractility of circular and longitudinal muscle in TNBS-inflamed guinea pig ileum. Am J Physiol 1997; 272: G1258-G1267.

14. Ohkusa T, Okayasu I, Tokoi S, Araki A, Ozaki Y. Changes in bacterial phagocytosis of macrophages in experimental alcerative colitis. Digestion 1995; 56: 159-164.

15. Boughton-Smith NK, Evans SM, Hawkey CJ, Cole AT, Balsitis M, Whittle BJR, Moncada S. Nitric oxide synthese activity in ulcerative colitis and Crohn's disease. Lancet 1993; 342: 338-340.

16. Iversen HH, Wiklund NP, Olgart C, Gustafsson LE. Nerve stimulationinduced nitric oxide release as a consequence of muscarinic $M_{1}$ receptor activation. Eur J Pharmacol 1997; 331: 213-219.

17. Barnes PJ, Haddad EB, Rousel J. Regulation of muscarinic $M_{2}$ receptors. Life Sci 1997; 60: 1015-1021.

ACKNOWLEDGEMENTS. At the time study H.v.W. was a medical student of the Erasmus University Rotterdam and P.A. a pharmacy student of the Unive rsity of Utrecht.

\section{Received 9 March 1998; accepted in revised form 8 May 1998}




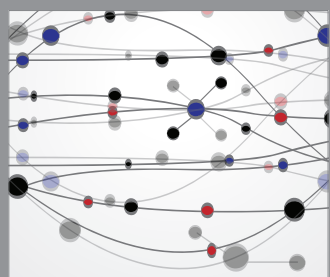

The Scientific World Journal
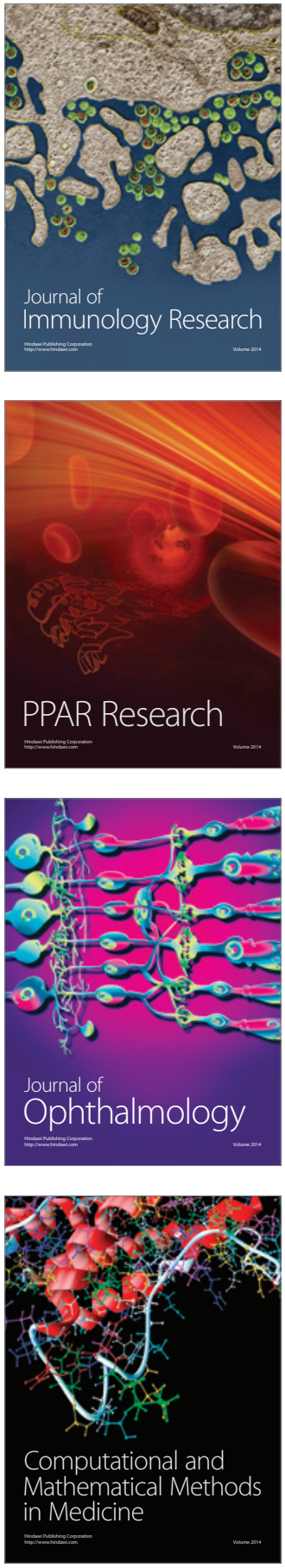

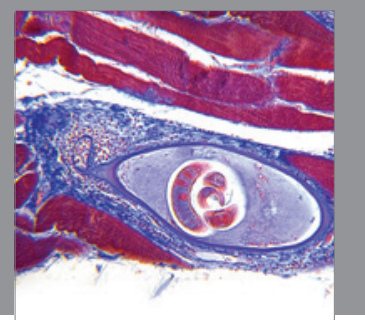

Gastroenterology

Research and Practice
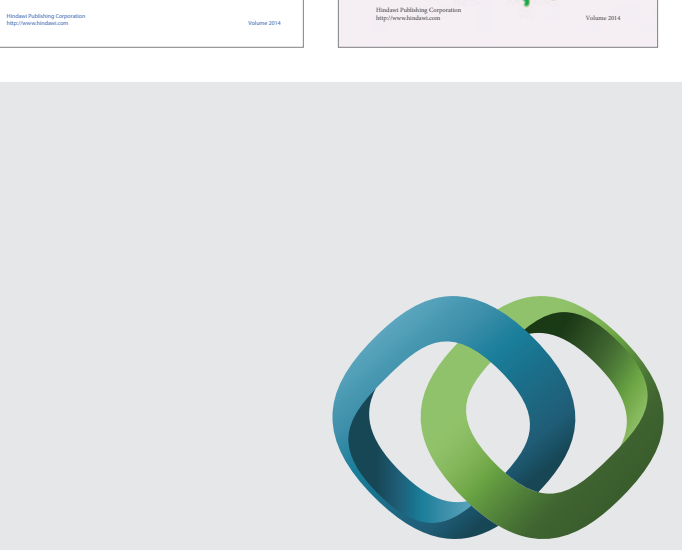

\section{Hindawi}

Submit your manuscripts at

http://www.hindawi.com
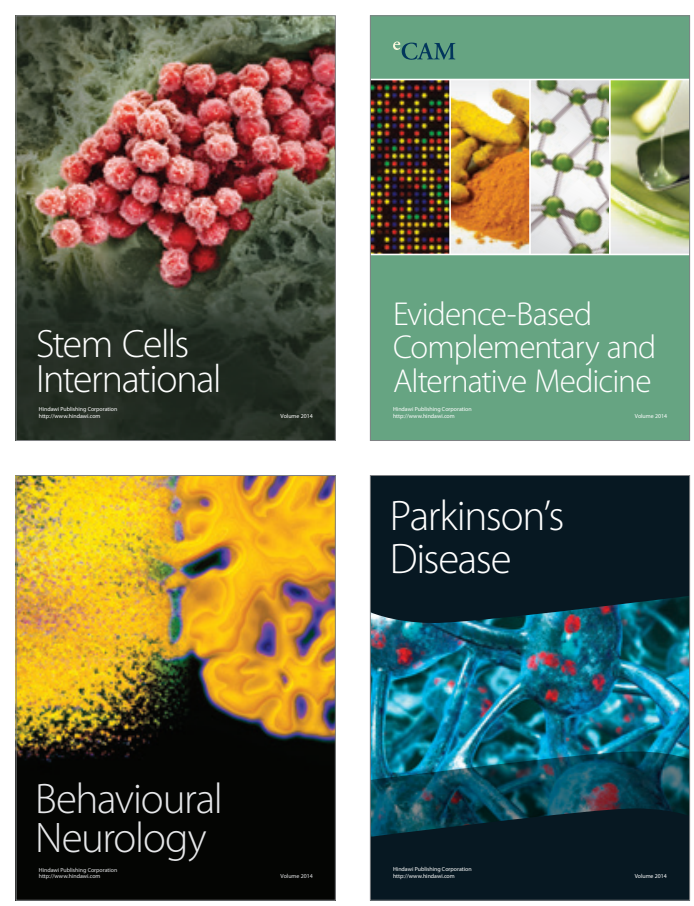

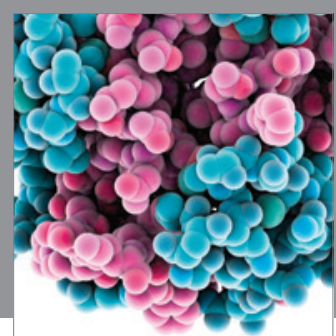

Journal of
Diabetes Research

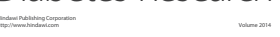

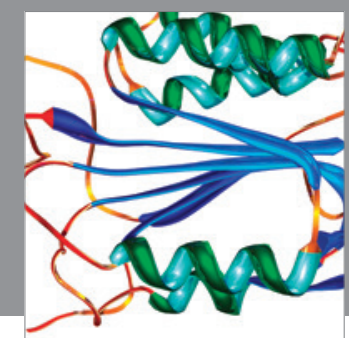

Disease Markers
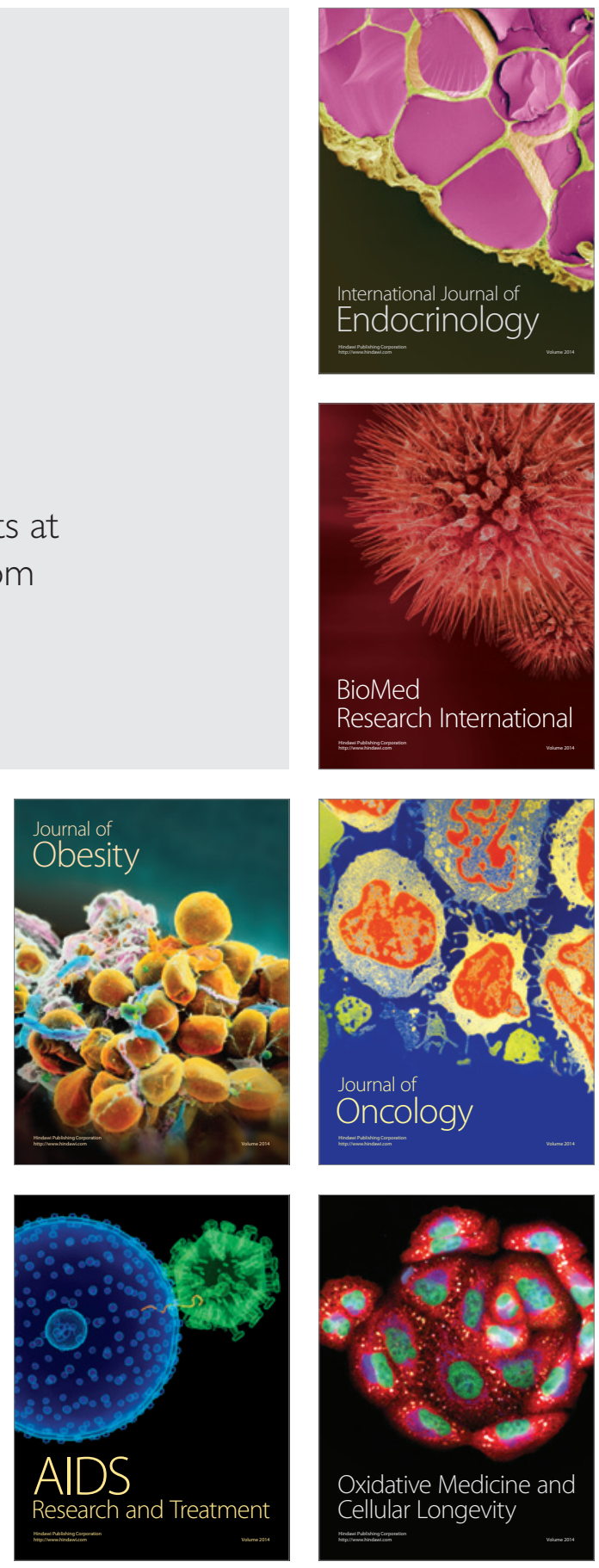